\title{
Housing system may affect behavior and growth performance of Jersey heifer calves
}

\author{
J. A. Pempek, M. L. Eastridge, ${ }^{1}$ S. S. Swartzwelder, K. M. Daniels, ${ }^{2}$ and T. T. Yohe $^{2}$ \\ Department of Animal Sciences, The Ohio State University, Columbus 43210
}

\section{ABSTRACT}

Social pressure is increasing to adopt alternative housing and management practices that allow farm animals more opportunity to exercise and demonstrate social behavior. The present study investigated the effect of pair housing on the behavior and growth performance of Jersey heifer calves. Forty female Jersey calves were allocated to individual or pair housing at birth and monitored for 9 wk. Calves were provided with a single hutch, and those allocated to the pair housing treatment were provided a pen enclosure twice the size of individually housed calves and only one hutch was provided per pair. All calves were fed milk replacer via bucket twice per day $(1.89 \mathrm{~L} /$ feeding first $7 \mathrm{~d} ; 2.27$ $\mathrm{L} /$ feeding until weaned) and had ad libitum access to grain and water. Gradual weaning commenced on d 49 by reducing the calves' milk allowance to one feeding per day, and weaning occurred on d 56. Grain consumption was monitored daily and calves were weighed weekly. Direct behavioral observations were conducted twice per week. Calves housed in pairs tended to have greater average daily gain compared with calves housed individually (0.63 vs. $0.59 \pm 0.02 \mathrm{~kg} / \mathrm{d}$, respectively). Pair housing also increased final body weight compared with individual housing (64.9 vs. $61.7 \pm 0.59 \mathrm{~kg}$, respectively). During observation periods, calves housed individually spent more time engaging in nonnutritive sucking than calves housed in pairs (21.5 vs. $8.15 \pm$ $0.03 \%$ of total observations). Calves housed in pairs were observed cross sucking $13.5 \%$ of the time during observational periods. Although housing Jersey calves in pairs may increase measures of growth performance, future research should aim to reduce cross-sucking behavior within the Jersey breed through alternative feeding systems or environmental enrichment.

Received July 8, 2015

Accepted September 13, 2015.

${ }^{1}$ Corresponding author: eastridge.1@osu.edu

${ }^{2}$ Current address: Department of Dairy Science, Virginia Polytechnic Institute and State University, Blacksburg, VA 24061.
Key words: animal welfare, Jersey calf, housing method, calf behavior

\section{INTRODUCTION}

Modern dairy production is sometimes criticized for on-farm procedures including early separation of the calf from the dam ( $<24 \mathrm{~h}$ after birth) and individually housing preweaned heifer calves (as opposed to housing in pairs or groups; Rushen et al., 2010). In a recent survey (USDA, 2012), 78.9\% of respondents reported that they housed preweaned heifer calves individually, with $42.1 \%$ of the population being housed outside, $10.5 \%$ housed inside with heat, and $26.3 \%$ housed inside without heat. This is in contrast to $15.9 \%$ of survey respondents that reported housing preweaned animals in any kind of group facilities. Although common, individual housing has been criticized due to restricted space and social isolation from other animals, and state and federal governments are increasingly being pressured to move toward alternative housing standards (Rollin, 1996; Croney and Millman, 2007; Croney and Anthony, 2011).

Historically, the dairy industry favored housing preweaned calves individually to reduce disease transmission (Gulliksen et al., 2009). However, in the past 2 decades, experiments conducted to evaluate calf health status when housed individually or in groups have challenged this traditional claim (Kung et al., 1997; Chua et al., 2002). For example, Chua et al. (2002) examined the health status of preweaned heifer calves housed individually or in pairs and reported no differences in health status between individual and pairhoused calves with all calves remaining healthy with no incidence of diarrhea. Similarly, Kung et al. (1997) reported that fewer days of medication were provided to calves housed in small groups compared with those housed individually in hutches, suggesting that grouping calves does not increase the likelihood of disease transmission, frequency, or duration of treatments.

Housing preweaned heifer calves in pairs or small groups may also be advantageous during the cold winter months, as cold temperatures impair the absorption 
of colostral immunoglobulins and increase the calves' susceptibility to disease (Vasseur et al., 2009). Soberon et al. (2012) also reported that preweaning ADG and first-lactation milk yield are negatively affected by the average ambient temperature at birth; calves born during the colder months $\left(0.2^{\circ} \mathrm{C}\right)$ produced $532 \mathrm{~kg}$ less milk than calves born within thermoneutral conditions. Young dairy calves are subject to hypothermia or cold stress when environmental temperatures fall below 10 to $20^{\circ} \mathrm{C}$ (Scibilia et al., 1987), and small breed calves (i.e., Jersey) are more susceptible to cold stress than large breed calves (i.e., Holstein) because of their large surface area (SA) relative to their BW. Thus, housing calves in pairs or small groups may promote the maintenance of core body temperature and reduce the animal's susceptibility to hypothermic conditions; 2 or more animals together can modify the effects of a fall in ambient temperature by huddling (Ingram and Mount, 1975).

From a behavioral standpoint, individual housing systems prevent calves from making physical contact with conspecifics, thus impeding social development, which can result in increases in fearful and aggressive behaviors toward novel conspecifics after grouping (Bøe and Færevik, 2003; Rushen et al., 2010). Because of the natural complex hierarchies established by dairy cattle, it is important for calves to learn how to interact socially with conspecifics (Jensen et al., 1999). Gaillard et al. (2014) recently reported that individual rearing (as opposed to group rearing) results in cognitive impairments in young dairy calves as assessed by calf performance in a reversal learning task. Gaillard et al. (2014) trained calves to associate a white- or blackcolored stimulus with a food reward, and once calves reached the appropriate learning criterion, the colors were reversed (i.e., calves that were initially trained to associate the white stimulus with the reward then had the reward paired with the black stimulus and vice versa). Pair-housed calves were better able to adapt and modify their behavior to obtain the food reward after the stimuli were reversed, yet individually housed calves continued to choose the incorrect stimulus. Social contact with conspecifics introduces variability into the environment, and the authors suggested that individually housed calves lacked behavioral flexibility (Coppens et al., 2010) or the ability of an animal to alter their behavior to changing environmental stimuli. In addition, De Paula Vieira et al. (2010) demonstrated that calves that are group-housed before weaning are also better able to learn how to use automated feeding equipment after weaning, as they visit the feeder more often and ingest more grain than calves that were previously housed individually. Thus, individual rearing during the preweaning period may reduce behavioral flexibility and limit the calves' ability to cope with novel situations or changes within their environment later in life.

In contrast, social interactions may result in poor welfare for the individual calf as calves are able to express undesirable behaviors such as cross sucking on one another. Cross-sucking is defined as an abnormal behavior wherein nonnutritive sucking directed toward another calf's ears, mouth, navel, scrotum, prepuce, or other body parts occurs (de Wilt, 1985), and this behavior stems from redirection of the calf's innate desire to suckle (Jensen, 2003). One reason dairy producers are reluctant to adopt modern group-housing systems is because this behavior may cause hair loss, inflammation, or infection of the body part exposed to cross sucking (Lidfors, 1993). Jersey cattle are an important breed to evaluate in a group setting, as the Jersey breed has been identified to have heightened cross-sucking behavior and are more frequently observed performing oral stereotypic behaviors, such as tongue-rolling and intersucking, compared with other breeds (Lidfors and Isberg, 2003). However, to date, the majority of studies have been conducted with Holstein calves, and it is currently unknown if Jersey calves will behave the same as Holstein calves when pair-housed. The duration, frequency, or both of cross-sucking behavior have yet to be quantified for group or pair-housed Jersey calves. Behavioral differences among breeds of other species, such as aggression in pigs (Breuer et al., 2003), are known to exist; therefore, it is inappropriate to assume that all breeds of dairy calves behave in the same manner when housed similarly.

The objective of this experiment was to compare the behavior, growth performance, and health of Jersey heifer calves housed individually or in pairs. We hypothesized that cross-sucking behavior would occur in pair-housed calves, as the Jersey breed appears to have a higher frequency of performing this behavior compared with Holstein calves. In addition, we hypothesized that pair-housed calves would have increased measures of growth performance compared with individually housed calves in part due to social facilitation.

\section{MATERIALS AND METHODS}

This study was conducted at The Ohio State University's Waterman Dairy Center, located in Columbus, Ohio, in accordance with guidelines set by the Institutional Animal Care and Use Committee (protocol no. 2012A00000099). Forty female Jersey calves born between August 2012 and February 2013 were used in this study. Calves were blocked by date of birth and weight and allocated to 1 of 2 treatments: treatment 1 , individual housing; treatment 2, pair housing. At birth, 
calves were housed by designated treatment and monitored for $9 \mathrm{wk}(63 \mathrm{~d})$. All calves were housed in hutches (nontethered, wire pen enclosure) placed on loose gravel. Both individually $(\mathrm{n}=20$ calves $)$ and pair-housed ( $\mathrm{n}=20$ calves $)$ calves were provided with one hutch, and those allocated to the pair housing treatment were provided a pen enclosure twice the size of individually housed calves [individual housing: $1.22 \mathrm{~m} \times 1.17 \mathrm{~m}$ (1.43 m²/calf); pair housing: $1.22 \mathrm{~m} \times 2.39 \mathrm{~m}(1.46$ $\mathrm{m}^{2} /$ calf $\left.)\right]$. Only one hutch was provided to pair-housed calves due to the calves' tendency to remain in the same hutch over $80 \%$ of the time when 2 hutches are provided (J. A. Pempek, unpublished data). Hutches were bedded with straw.

All calves received $1.9 \mathrm{~L}$ of maternal colostrum via bottle from Johne's negative dams as soon as possible after birth and again within $6 \mathrm{~h}$ of the first colostrum feeding per regular herd standard operating procedure. If acceptable-quality maternal colostrum, as measured by colostrometer, was not readily available for use, replacement colostrum (bovine IgG, colostrum replacement; Land O'Lakes Animal Milk Products, St. Paul, $\mathrm{MN}$ ) was fed to the calf.

\section{Total Serum Protein}

Blood samples were collected in 5-mL Vacutainer serum collection tubes (BD Vacutainer Plus Blood Clot Collection Tubes, Becton Dickinson Co., Franklin Lakes, NJ) via jugular venipuncture within $48 \mathrm{~h}$ after calves were fed colostrum. The blood samples were immediately placed on ice after collection and transported to the laboratory within $1 \mathrm{~h}$. Samples were centrifuged at $1,180 \times g, 4^{\circ} \mathrm{C}$ for $15 \mathrm{~min}$. Total serum protein was analyzed using a JorVet clinical handheld refractometer (Jorgesen Laboratories Inc., Loveland, CO) and used as a measure to assess passive transfer of immunity, attained through colostrum feeding.

\section{Feed}

Calves were fed milk replacer (MR; Cow's Match Jersey Blend; $28 \% \mathrm{CP}$ and 25\% fat, as-fed basis; Land O'Lakes Animal Milk Products) twice daily at approximately 0600 and $1700 \mathrm{~h}$ in buckets. The buckets were removed as soon as the calves completed their MR meal, and it was ensured that calves housed in pairs had access to MR simultaneously. During the first $7 \mathrm{~d}$ of life, calves were fed $1.89 \mathrm{~L}(0.28 \mathrm{~kg})$ of MR per feeding, which was increased to $2.27 \mathrm{~L}(0.34 \mathrm{~kg})$ per feeding thereafter. Gradual weaning began on d 49, as calves were decreased to one MR feeding (morning only) per day, and all calves were weaned on d 56. Calves had ad libitum access to a texturized grain (22\% CP; AMPLICalf Jersey Blend, Land O'Lakes Purina Feed, LLC, Shoreview, MN) medicated with $44 \mathrm{~g} / \mathrm{t}$ of monensin (Rumensin, Elanco Animal Health, Greenfield, IN) and water throughout the experiment. Grain consumption was recorded daily by the collection of feed refusals before the evening MR feeding. Feed refusals for pairhoused calves were averaged because it was not possible to monitor individual feed intake. Water intake was not measured.

\section{Behavior Observations}

Calf behavior was recorded by direct observation using instantaneous scan-sampling with 60-s intervals (Jensen and Budde, 2006). Observation periods were conducted twice per week ( $1 \mathrm{~h}$ session duration) and were centered around one morning and one evening MR feeding period (approximately 0600 and $1700 \mathrm{~h}$ ). Scan sampling began 30 min before the delivery of MR and ended $30 \mathrm{~min}$ after MR delivery to calves. The scan sample period length for each animal was approximately $5 \mathrm{~s}$, and only the initial posture (standing or lying) and behavioral state (nonnutritive sucking, locomotor play, object play, self-grooming, ingesting grain, water or milk, cross sucking, allogrooming, social play, or other) of the calf were recorded. The recorded behaviors are listed and defined in Table 1.

Three observers were used to collect the behavioral data. To evaluate inter-observer reliability, each observer scored the behavior of the same group of calves over 2 observation periods before the initiation of individual observation. Pearson correlations among each pair of observers were high (range of $\mathrm{r}=0.93-0.96$; all $P<$ $0.001)$.

\section{Growth Performance and Health}

All calves were weighed at birth and weekly thereafter. In addition, hip height $(\mathbf{H H})$, withers height, and body length measurements were taken at birth and 3 , 6 , and 9 wk of age.

Fecal scores (Diaz et al., 2001) and rectal body temperature were recorded daily at $1500 \mathrm{~h}$ each day for the entire 63-d trial. When calves were diagnosed as ill or having a fecal score of 3 or greater, they were treated per veterinarian recommendations, primarily using an oral electrolyte solution (Entrolyte H.E., Pfizer Animal Health, New York, NY), antibiotics, or both. If a calf's body temperature was $\geq 39.4^{\circ} \mathrm{C}, 2 \mathrm{~mL}$ of Flu-nix (Agri Laboratories Ltd., St. Joseph, MO) was administered intravenously. When pyrexia was not alleviated in response to the Flu-nix treatment, the calf received 2 
Table 1. Ethogram of the recorded behaviors and their description

\begin{tabular}{|c|c|}
\hline Behavior & Description \\
\hline Standing & The calf is standing with all 4 legs on the ground. \\
\hline Other & The calf is ruminating, urinating, defecating, or performing another behavior not described. \\
\hline Locomotor play & The calf is engaged in a gallop, leap, buck-low, buck-high, buck-kick, or turn. \\
\hline Object play & The calf is standing; butting head against milk or water buckets or hutch in a playful manner. \\
\hline Ingesting water & The calf is ingesting water by drinking from a bucket. \\
\hline Ingesting milk & The calf is ingesting milk by drinking from a bucket. \\
\hline Cross-sucking & $\begin{array}{l}\text { Pair-housed calves only-The calf is sucking on the body of another calf; the sucking movements are performed } \\
\text { with the body part in the mouth. }\end{array}$ \\
\hline Allogrooming & $\begin{array}{l}\text { Pair-housed calves only-The calf's tongue is out of its mouth and in contact with the head, neck, or body of the } \\
\text { companion calf. }\end{array}$ \\
\hline Social play & $\begin{array}{l}\text { Pair-housed calves only—The calves are standing front-to-front; butting head against head/neck in a playful } \\
\text { manner. }\end{array}$ \\
\hline
\end{tabular}

mL of Excenel (Pharmacia \& Upjohn Co., Pfizer Inc., New York, NY) intramuscularly. Type and duration of treatment were recorded for all calves.

To examine the accuracy of a wireless data logger as a noninvasive alternative to monitoring core body temperature rectally, wireless data loggers (Thermochron iButton DS1922T, Maxim Integrated, San Jose, CA) were adhered to the underside of calves' tails $(\mathrm{n}=8)$ with medical tape and further secured with VetWrap cohesive bandage (3M Products, St. Paul, MN). Each iButton was set to record the calf's temperature once every 15 min to observe daily temperature variation throughout the experiment. The rectal body temperature was then matched to the $1500 \mathrm{~h}$ recorded skin temperature.

\section{Environmental Factors}

AcuRite Wireless Digital Thermometers (Lake Geneva, WI) were secured within suet wire baskets (Kaytee Cake Feeder Station, Chilton, WI) for protection and mounted directly above the straw bedding in the back of each hutch to monitor daily interior hutch temperature (maximum and minimum). In addition, weather data were collected from the National Oceanic and Atmospheric Administration's National Weather Service (Columbus, OH) for all days of the experimental period. The monthly means for each month were weighted based on the number of days calves were enrolled in the study for each respective month.

\section{Statistical Analysis}

Data were analyzed as a randomized complete block design with repeated measures in time using the MIXED procedure of SAS (version 9.3, SAS Institute Inc., Cary,
$\mathrm{NC})$. One pair was separated after wk 3 of the experiment due to an aural hematoma; these data were still included as a pair for the analysis with missing data points after wk 3 . The covariance structures of error for behavior and growth performance and health repeated measures were selected based on the lowest Bayesian information criterion. Least squares means and standard errors were determined using the LSMEANS statement in the MIXED procedure. Significant differences were declared at $P \leq 0.05$ and a trend at $0.05>P \leq 0.10$.

Behavior Analysis. Because the main effect of treatment did not vary across experimental week, these data were combined to provide one morning and one evening behavior observation period per calf for statistical analyses. The model included the fixed effects of treatment ( $1 \mathrm{df})$, observation period $(1 \mathrm{df})$, treatment $\times$ observation period interaction $(1 \mathrm{df})$, and the random effect of block ( $9 \mathrm{df})$. Calf within treatment by block was used as the experimental unit. To obtain normality, the mean proportion of the behaviors displayed by all calves, independent of housing treatment, was transformed using the arcsin transformation (Snedecor and Cochran, 1967), and all transformed data were back-transformed for reporting. The selected covariance structure of error was the banded main diagonal [UN(1)] structure.

Growth Performance and Health Analysis. The model included the fixed effects of treatment $(1 \mathrm{df})$, week of experiment ( $8 \mathrm{df})$, treatment by week interaction $(8 \mathrm{df})$, and the random effect of block (9 df). Calf within treatment by block was used as the experimental unit. Birth measurements were used for covariate adjustment of data. The selected covariance structure of error was the first-order autoregressive [AR(1)] structure. The equations used to calculate body SA were $0.14 \times \mathrm{BW}^{0.57}\left(\right.$ Brody, 1945) and $0.09 \times \mathrm{BW}^{0.67}$ 
Table 2. Least squares means for percentage of time calves engaged in each of the behaviors measured

\begin{tabular}{lcccc}
\hline Behavior (\% of total time) & Individual & Pair & SEM & $P$-value \\
\hline Lying & 24.7 & 25.6 & 0.03 & 0.73 \\
Standing & 70.5 & 74.2 & 0.10 & 0.37 \\
Idle & 57.1 & 60.7 & 0.03 & 0.17 \\
Other & 0.37 & 0.28 & 0.004 & 0.36 \\
Nonnutritive sucking & 21.5 & 8.15 & 0.03 & $<0.0001$ \\
Locomotor play & 1.02 & 0.66 & 0.01 & 0.11 \\
Object play & 1.36 & 0.21 & 0.01 & $<0.0001$ \\
Self-grooming & 1.94 & 0.67 & 0.01 & $<0.001$ \\
Ingesting grain & 4.14 & 4.63 & 0.01 & 0.39 \\
Ingesting water & 0.76 & 0.55 & 0.003 & 0.11 \\
Ingesting milk & 4.86 & 4.20 & 0.002 & 0.01 \\
Cross-sucking & - & 13.5 & 0.02 & - \\
Allogrooming & - & 0.30 & 0.010 & - \\
Social play & - & 0.06 & 0.003 & - \\
\hline
\end{tabular}

(Mitchell, 1928). The correlations among body SA and growth performance variables were determined using PROC CORR of SAS. Due to the low level of occurrence, morbidity data were summarized descriptively.

The REG procedure of SAS was used to conduct a regression analysis to determine if tail skin temperature could be used as an accurate predictor of calf rectal temperature. The final data set used 430 paired observations and included tail skin temperature as the regressor variable and rectal temperature as the outcome variable.

Environmental Factors Analysis. The effects of housing treatment on average internal hutch temperature (below $10^{\circ} \mathrm{C}$ ) and days below $10^{\circ} \mathrm{C}$ were also compared. The model included the fixed effects of treatment $(1 \mathrm{df})$ and the random effect of block (9 df).

\section{RESULTS}

\section{Behavior}

Behavior results revealed that the posture of calves housed in pairs was similar to the posture of calves housed individually (Table 2). During periods of observation, calves housed individually spent more time engaged in nonnutritive sucking compared with calves housed in pairs $(21.5$ vs. $8.15 \pm 0.03 \%$ of total observations). However, calves housed in pairs were observed cross sucking ( $13.5 \%$ of total observations), which occurred predominantly after the completion of their MR meal. Locomotor play, object play, and self-grooming behaviors were observed less frequently than nonnutritive sucking, yet calves housed individually were observed performing object play and self-grooming behaviors more often than calves housed in pairs (Table 2 ). In addition, calves housed in pairs consumed their milk meal faster than calves housed individually (4.20 vs. $4.86 \pm 0.0002 \%$ of total observations). However, no differences were observed between the amount of time that calves spent consuming grain and water (Table 2). Lastly, affiliative behaviors, such as allogrooming and social play, were rarely observed among calves housed in pairs during periods of observation (0.30 and $0.06 \%$ of total observations, respectively).

\section{Growth Performance and Health}

Although housing Jersey heifer calves in pairs did not significantly increase overall mean BW (Table 3), a treatment by time interaction $(P=0.05)$ revealed that calves housed in pairs tended to weigh more than individually housed calves during wk 7 and 8 (Figure 1 ), and calves housed in pairs completed the experiment with a greater final BW compared with calves housed individually ( 64.9 vs. $61.7 \pm 0.59 \mathrm{~kg})$. In addition, ADG tended to be higher for pair-housed calves compared with calves housed individually (Table 3). Overall grain DMI did not differ between treatments, yet a treatment by time interaction (Figure 2) revealed that calves housed in pairs consumed more grain during wk 9 than calves housed individually (2.36 vs. $2.12 \pm$ $0.05 \mathrm{~kg} / \mathrm{d}$ ).

Calves housed in pairs were taller at the withers compared with calves housed individually (74.7 vs. $74.1 \pm$ $0.23 \mathrm{~cm}$ ). However, the $\mathrm{HH}$ of calves were similar between treatments (Table 3). Body length measurements also did not differ among treatments, yet an approaching tendency was found for pair-housed calves to grow more from the withers to the pins than individually housed calves ( 56.1 vs. $55.2 \pm 0.37 \mathrm{~cm} ; P=0.11$ ).

The equations used to calculate body SA derived by Brody (1945) and Mitchell (1928) were highly correlated with one another (Table 4). As expected, calf BW had the strongest relationship with body SA $(r=0.998$; $P<0.0001)$. Also, both withers height and HH shared a strong, positive relationship with body SA (Table 
Table 3. Least squares means of average daily gain, grain dry matter intake, withers height, hip height, and body length measurements for calves housed individually or in pairs during the milk feeding and weaning periods $(63 \mathrm{~d})$

\begin{tabular}{lcccc}
\hline Variable & Individual & Pair & SEM & $P$-value \\
\hline ADG $(\mathrm{kg} / \mathrm{d})$ & 0.59 & 0.63 & 0.02 & 0.09 \\
Grain DMI (kg/d) & 0.67 & 0.72 & 0.05 & 0.44 \\
Withers height $(\mathrm{cm})$ & 74.1 & 74.7 & 0.23 & 0.02 \\
Hip height $(\mathrm{cm})$ & 76.9 & 76.9 & 0.23 & 0.85 \\
Shoulders to pins $(\mathrm{cm})$ & 65.3 & 65.2 & 0.32 & 0.88 \\
Withers to pins $(\mathrm{cm})$ & 55.2 & 56.1 & 0.37 & 0.11 \\
\hline
\end{tabular}

4). Lastly, although both body length measurements were highly correlated with body SA, the measurement from the shoulders to the pins resulted in a slightly higher correlation with body SA $(\mathrm{r}=0.93 ; P<0.0001)$ compared with the withers to the pins $(\mathrm{r}=0.90 ; P<$ 0.0001).

All calves had a total serum protein concentration $>5.5 \mathrm{~g} / \mathrm{dL}$, which did not differ by treatment (Table 5). Calf fecal scores were not affected by housing treatment (Table 5). However, a significant week effect was present, as fecal score increased with age from 1.33 during wk 1 to 2.98 during wk 9 . Rectal body temperature also did not differ by treatment (Table 5), yet a significant week effect was found; calves' rectal body temperature decreased slightly with age.

Rectal temperature $\left({ }^{\circ} \mathrm{C}\right)$ was best predicted as $37.6 \pm$ $0.75+(0.03 \pm 0.02 \times$ Thermochron iButton temperature) $\left({ }^{\circ} \mathrm{C}\right)$. This equation had an $\mathrm{R}^{2}$ value of 0.01 and root mean square error of 0.37 , indicating that tail skin temperature is not an accurate predictor of calf core body temperature $(P=0.10)$.

\section{Environmental Factors}

The mean ambient high and low temperatures throughout the duration of the experiment are listed in Table 6; average high temperatures ranged from 3.53 to $30.4^{\circ} \mathrm{C}$, and the average low temperatures ranged from -4.48 to $16.35^{\circ} \mathrm{C}$. When the internal hutch temperature fell below $10^{\circ} \mathrm{C}$, the average environmental temperature did not differ by housing treatment; calves housed in pairs and calves housed individually experienced similar thermal conditions when the temperature fell below the thermoneutral zone $\left(3.58\right.$ vs. $\left.3.59^{\circ} \mathrm{C}\right)$. In addition, the average number of days in which calves may have been exposed to cold-stress conditions did not differ by

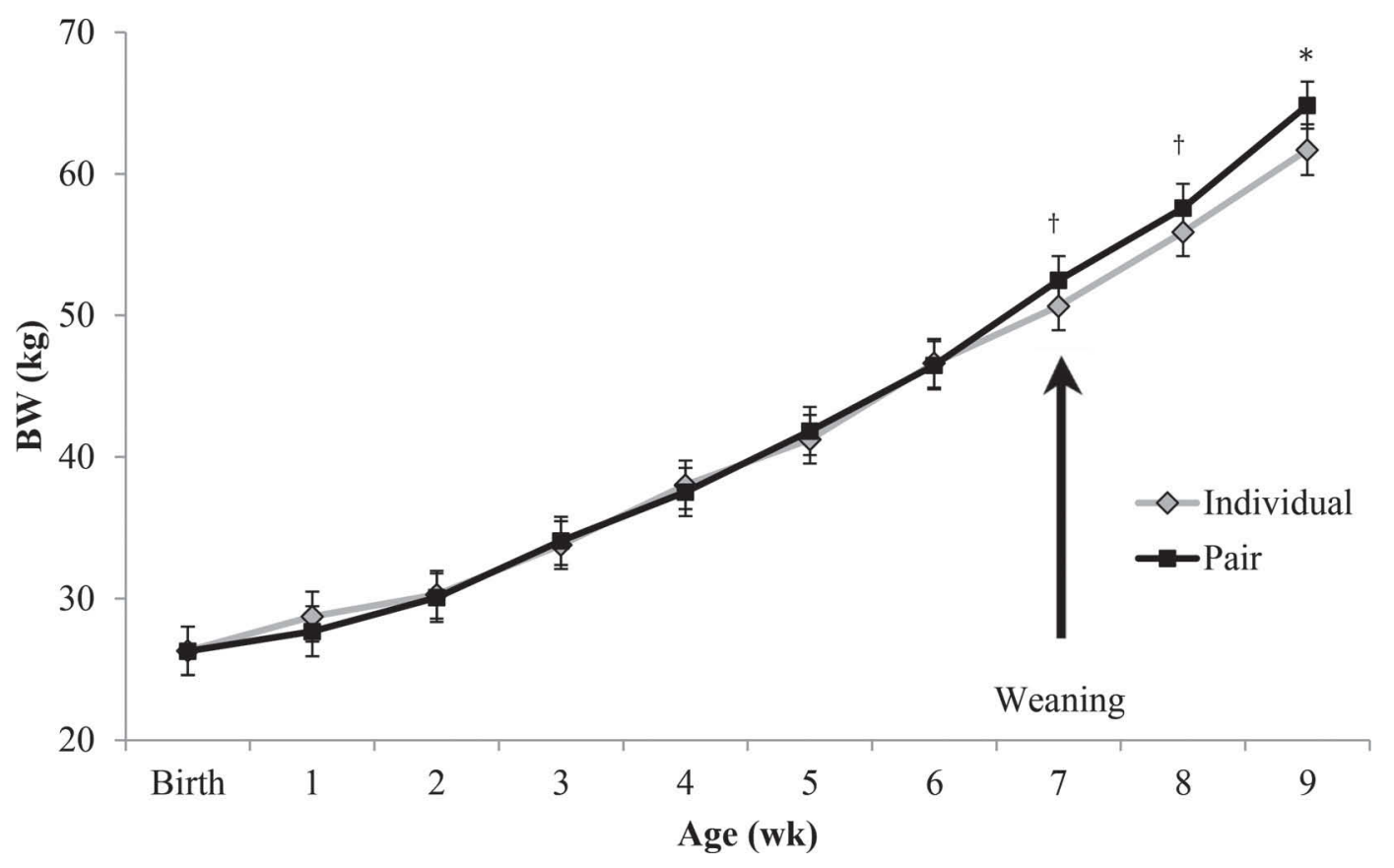

Figure 1. Body weight $( \pm$ SEM $)$ for calves housed in pairs $(\mathrm{n}=20$ calves $)$ or individually $(\mathrm{n}=20$ calves $)$ during the milk feeding and weaning periods. *Means within housing treatment were different $(P<0.05)$. † Means within housing treatment tended to differ $(P<0.10)$. 


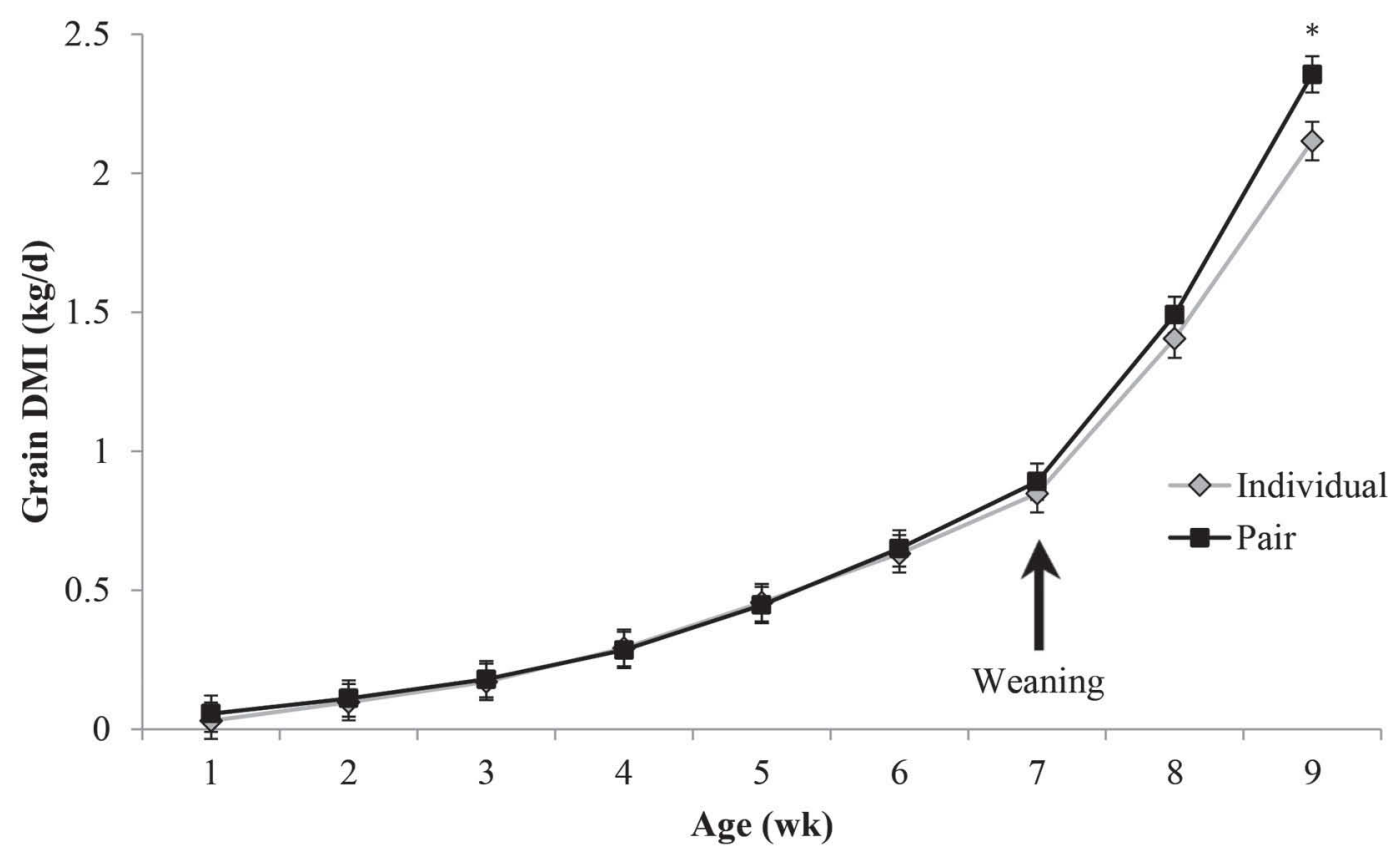

Figure 2. Grain DMI ( \pm SEM) for calves housed in pairs $(n=20$ calves $)$ or individually $(n=20$ calves $)$ during the milk feeding and weaning periods. * Means within housing treatment were different $(P<0.05)$.

housing treatment; calves housed in pairs experienced approximately $39.4 \pm 2.97 \mathrm{~d}$ below thermoneutral temperatures, whereas calves housed individually experienced $41.0 \pm 2.97 \mathrm{~d}$ below thermoneutral temperatures.

\section{DISCUSSION}

\section{Behavior}

In the current study, calves housed individually were observed to engage in nonnutritive sucking more often than calves housed in pairs. Nonnutritive sucking may be observed under natural conditions, yet it more commonly occurs within artificial rearing systems (Jensen, 2003). Although nonnutritive sucking was observed more often among individually housed calves, calves housed in pairs appeared to redirect this behavior to their companion calf as cross sucking. In our study, nonnutritive sucking and cross sucking were analyzed as separate behavioral variables. Yet, if such variables were combined and compared numerically, the behavioral occurrence is almost identical. It is also important

Table 4. Coefficients of simple correlations between surface area (SA) using 2 different equations, BW, ADG, wither height (WH), hip height (HH), and body length (BL) using 2 different measurements

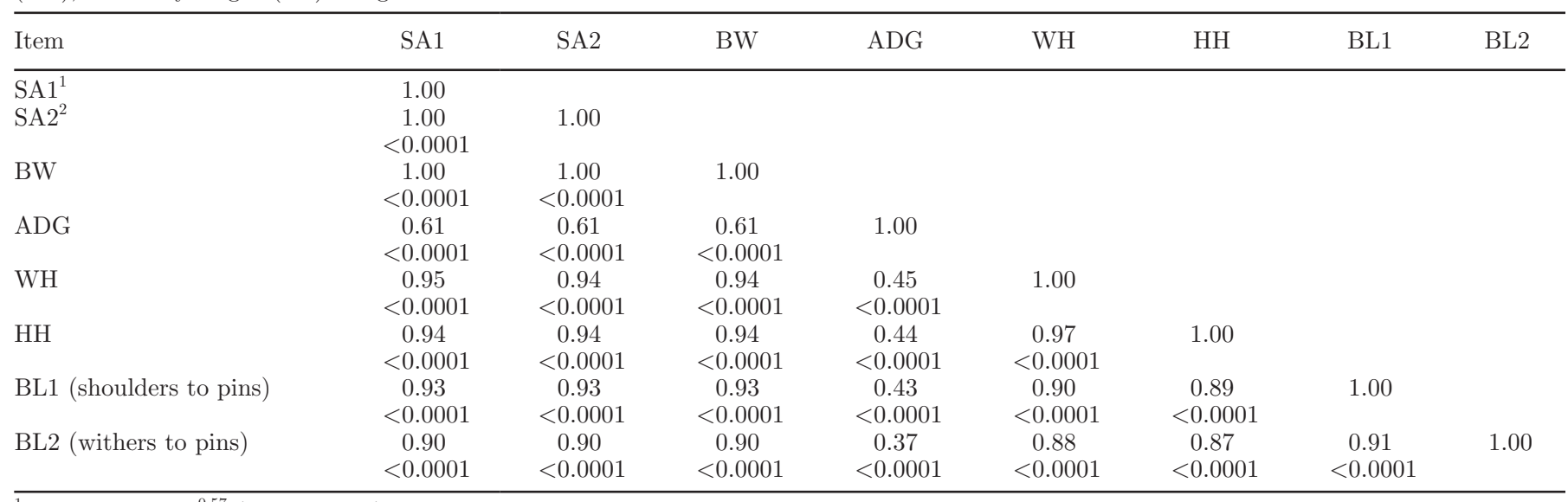

${ }^{1} \mathrm{SA} 1=0.14 \mathrm{BW}^{0.57}($ Brody, 1945).

${ }^{2} \mathrm{SA} 2=0.09 \mathrm{BW}^{0.67}$ (Mitchell, 1928). 
Table 5. Least squares means $( \pm \mathrm{SEM})$ of total serum protein within $48 \mathrm{~h}$ of birth and average fecal score (4-point scale) and rectal body temperature for calves housed individually or in pairs during the milk feeding and weaning periods

\begin{tabular}{lcccc}
\hline Variable & Individual & Pair & SEM & $P$-value \\
\hline Total serum protein $(\mathrm{g} / \mathrm{dL})$ & 7.22 & 7.02 & 0.21 & 0.35 \\
Fecal score $^{1}$ & 1.98 & 2.08 & 0.09 & 0.28 \\
Rectal body temperature $\left({ }^{\circ} \mathrm{C}\right)$ & 38.8 & 38.8 & 0.03 & 0.27 \\
\hline
\end{tabular}

${ }^{1}$ Diaz et al., 2001 [ $1=$ firm, well-formed (not hard); $2=$ soft, pudding-like; $3=$ runny, pancake batter; and 4 $=$ liquid, splatters].

to note that MR was provided via bucket in this study, which may have contributed to the heightened expression of nonnutritive sucking and cross sucking. Hammell et al. (1988) reported that such behaviors are independent of milk satiation, as calves fed MR ad libitum via bucket are still highly motivated to suck on an artificial teat after the completion of a milk meal. Thus, the young calf's motivation to suckle is inherently strong (de Passillé, 2001), and the inability to perform such behaviors that are intrinsic in nature may directly and indirectly affect animal welfare. A further consequence of the inability to suckle may be the development of stereotypical oral behaviors as an attempt to satisfy behavioral needs (Bergeron et al., 2006).

In the United States, bucket feeding is by far the predominant feeding method and is widely used for its convenience in the dairy industry. For instance, a recent survey conducted by the USDA (2012) reported $61.5 \%$ of feeding management systems employed the use of an open bucket for milk delivery, whereas only $26.9 \%$ of systems employed the use of a bottle fitted with a teat. Transitioning to a teat system for feeding could reduce nonnutritive sucking behaviors as demonstrated by Loberg and Lidfors (2001) and Jensen and Budde (2006). Further studies evaluating the difference in nonnutritive sucking behaviors among Jersey calves with a teat system should be conducted.

Calves housed in pairs engaged in cross-sucking behavior $13.5 \%$ of the observation period, which was

Table 6. Mean ambient temperature by month throughout the experimental period

\begin{tabular}{lcc}
\hline Month & $\begin{array}{c}\text { High } \\
\text { temperature }\left({ }^{\circ} \mathrm{C}\right)\end{array}$ & $\begin{array}{c}\text { Low } \\
\text { temperature }\left({ }^{\circ} \mathrm{C}\right)\end{array}$ \\
\hline August 2012 & 30.4 & 16.4 \\
September 2012 & 24.7 & 12.8 \\
October 2012 & 17.2 & 7.38 \\
November 2012 & 11.0 & 0.24 \\
December 2012 & 7.47 & 0.79 \\
January 2013 & 4.32 & -4.23 \\
February 2013 & 3.53 & -4.48 \\
March 2013 & 7.01 & -1.13 \\
April 2013 & 18.4 & 6.00 \\
\hline
\end{tabular}

${ }^{1}$ Mean temperatures include the days for which calves were on trial. predominantly directed toward the navel and the ears of the companion calf. In this study, one pair had to be permanently separated as a consequence of cross sucking resulting in an aural hematoma. In addition to this incident, frost bite, inflammation of navels, and one ear infection (Mycoplasma bovis) were also observed in pair-housed calves. This study demonstrates the significant effect cross sucking may have on the health and welfare of calves. In contrast to our results, few studies conducted with Holstein calves have reported cross sucking as being injurious to calf health (de Wilt, 1985; Chua et al., 2002; Babu et al., 2004). In those studies that did report negative effects to the health of the calves, the feeding system used was a bucket or trough (Margerison et al., 2003), similar to the feeding management system employed in this research study.

In conclusion, regardless of facility, calves spent a significant period of time performing nonnutritive sucking focusing on objects within the pen, the calf itself, and other calves. Future experiments should aim to reduce cross sucking and nonnutritive sucking behavior through alternative milk-feeding systems and the potential implementation of environmental enrichment devices. In addition, it may be of interest to investigate a potential association between cross-sucking behavior and the stereotypic tongue-rolling behavior, as Jersey cattle predominantly exhibit this oral stereotypic behavior when mature.

\section{Growth Performance and Health}

In the current experiment, disease prevalence, other than diarrhea, was minimal and did not differ between housing treatments. The ADG for calves regardless of treatment was comparable with Jersey calves in other studies, as well; Jensen (2006) reported an ADG of $0.594 \mathrm{~kg} / \mathrm{d}$. Housing Jersey heifer calves in pairs improved measures of growth performance with ADG tending to be higher for calves housed in pairs compared with calves housed individually and calves housed in pairs consuming more calf-starter during the week after weaning. Also, calves housed in pairs tended to have a higher BW during the weaning period, which 
significantly increased during the week after weaning. Our results agree with previous studies that also have reported increased weight gains for group-housed calves (Xiccato et al., 2001; Chua et al., 2002). Such improvements may be attributed to social facilitation to promote eating as group activity and early social interactions allow calves to learn at a faster pace than those reared individually or in isolation (Babu et al., 2004; Gaillard et al., 2014).

In addition, the weaning period is one of the most stressful periods in the life of young calves (Weary et al., 2008). Thus, social companionship may reduce the level of stress calves experience during this period and also minimize the often-observed slowed growth via social buffering (De Paula Vieira et al., 2010). For instance, De Paula Vieira et al. (2010) reported that pairhoused calves spent more time at the feeder, visited the feeder more often, and ingested more grain. The authors also reported that pair-housed calves showed a reduced vocal response to weaning compared with individually housed calves. Although the calves' behavioral response to weaning was not quantified in the present study, calves housed individually did not perform as well as pair-housed calves; calves housed individually consumed less grain directly following weaning and had a lower BW throughout and after weaning. Thus, this research supports the aforementioned studies conducted with Holstein heifer calves and suggests that housing Jersey calves in pairs also mitigates the stressors associated with weaning as young calves transition from milk to a solid diet.

\section{Environmental Factors}

The thermoneutral zone for young dairy calves is between 10 to $20^{\circ} \mathrm{C}$ (Scibilia et al., 1987), and when environmental temperatures drop below this threshold, calves must consume more nutrients for body maintenance (NRC, 2001). Environmental temperature below this range is considered one of the most commonly experienced stressors (Litherland et al., 2014). It was expected that when the internal hutch temperature fell below $10^{\circ} \mathrm{C}$, the lower range of the young calf's thermoneutral zone, the average temperature for calves housed in pairs would be higher than the temperature for calves housed individually. However, this initial hypothesis was incorrect, as our results indicated that the temperature within the hutch remained the same independent of treatment during potential periods of cold stress. In addition, although no difference was observed by treatment, calves experienced chilling or cold-stress over two-thirds of the experimental duration. This is an important management consideration, as the majority of Jersey heifer calves in this experiment experienced cold stress.

\section{CONCLUSIONS}

Housing Jersey heifer calves in pairs or in small groups allows for early social interactions and may increase measures of growth performance pre- and postweaning. Future research should aim to compare Holstein and Jersey breeds behaviorally and reduce cross-sucking and nonnutritive sucking behavior specifically by using alternative feeding systems, environmental enrichment, or both. In addition, a noninvasive proxy for core body temperature in preweaned calves is still needed because tail skin temperature is not a viable alternative.

\section{ACKNOWLEDGMENTS}

The authors are thankful for the cooperation of the students and staff of Waterman Dairy Center (Columbus, $\mathrm{OH}$ ) and for their assistance throughout this research trial. We also wish to express gratitude to the American Jersey Cattle Association (Reynoldsburg, $\mathrm{OH})$ for their partial funding for this research.

\section{REFERENCES}

Babu, L. K., H. N. Pandey, and A. Sahoo. 2004. Effect of individual versus group rearing on ethological and physiological responses of crossbred calves. Appl. Anim. Behav. Sci. 87:177-191.

Bergeron, R., A. J. Badnell-Waters, S. Lambton, and G. Mason. 2006. Stereotypic oral behaviour in captive ungulates: Foraging, diet and gastrointestinal function. Pages 19-57 in Stereotypic Animal Behaviour: Fundamentals and Application to Welfare. G. Mason and J. Rushen, ed. CABI Publishing, Wallingford, UK.

Bøe, K. E., and G. Færevik. 2003. Grouping and social preferences in calves, heifers and cows. Appl. Anim. Behav. Sci. 80:175-190.

Breuer, K., M. E. M. Sutcliffe, J. T. Mercer, K. A. Rance, V. E. Beattie, I. A. Sneddon, and S. A. Edwards. 2003. The effect of breed on the development of adverse social behaviours in pigs. Appl. Anim. Behav. Sci. 84:59-74.

Brody, S. 1945. Chapter 13.2: Basal metabolism and the "surface law." Pages 354-403 in Bioenergetics and Growth with Special Reference to the Energetic Efficiency Complex in Domestic Animals. Reinhold Publ., New York, NY.

Chua, B., E. Coenen, J. van Delen, and D. M. Weary. 2002. Effects of pair versus individual housing on the behavior and performance of dairy calves. J. Dairy Sci. 85:360-364.

Coppens, C. M., S. F. de Boer, and J. M. Koolhaas. 2010. Coping styles and behavioural flexibility: Towards underlying mechanisms. Phil. Trans. R. Soc. B 365:4021-4028.

Croney, C. C., and R. Anthony. 2011. Invited review: Ruminating conscientiously: Scientific and socio-ethical challenges for US dairy production. J. Dairy Sci. 94:539-546.

Croney, C. C., and S. T. Millman. 2007. Board-Invited Review: The ethical and behavioral bases for farm animal welfare legislation. J. Anim. Sci. 85:556-565.

de Passillé, A. M. B. 2001. Sucking motivation and related problems in calves. Appl. Anim. Behav. Sci. 72:175-187.

De Paula Vieira, A., M. A. G. von Keyserlingk, and D. M. Weary. 2010. Effects of pair versus single housing on performance and 
behavior of dairy calves before and after weaning from milk. J. Dairy Sci. 93:3079-3085.

de Wilt, J. G. 1985. Behaviour and welfare of veal calves in relation to husbandry systems. PhD Diss. Agric. Univ. of Wageningen, the Netherlands.

Diaz, M. C., M. E. Van Amburgh, J. M. Smith, J. M. Kelsey, and E. L. Hutten. 2001. Composition of growth of Holstein calves fed milk replacer from birth to 105-kilogram body weight. J. Dairy Sci. 84:830-842.

Gaillard, C., R. K. Meagher, M. A. von Keyserlingk, and D. M. Weary. 2014. Social housing improves dairy calves' performance in two cognitive tests. PLoS ONE 9:e90205.

Gulliksen, S. M., K. I. Lie, T. Løken, and O. Østerås. 2009. Calf mortality in Norwegian dairy herds. J. Dairy Sci. 92:2782-2795.

Hammell, K. L., J. H. M. Metz, and P. Mekking. 1988. Sucking behaviour of dairy calves fed milk ad libitum by bucket or teat. Appl. Anim. Behav. Sci. 20:275-285.

Ingram, D. L., and L. E. Mount. 1975. Man and Animals in Hot Environments. Springer-Verlag, New York, NY.

Jensen, M. B. 2003. The effects of feeding method, milk allowance and social factors on milk feeding behaviour and cross-sucking in group housed dairy calves. Appl. Anim. Behav. Sci. 80:191-206.

Jensen, M. B. 2006. Computer-controlled milk feeding of group-housed calves: The effect of milk allowance and weaning type. J. Dairy Sci. 89:201-206.

Jensen, M. B., and M. Budde. 2006. The effects of milk feeding method and group size on feeding behavior and cross-sucking in grouphoused dairy calves. J. Dairy Sci. 89:4778-4783.

Jensen, M. B., L. Munksgaard, L. Mogensen, and C. C. Krohn. 1999 Effects of housing in different social environments on open-field and social responses of female dairy calves. Acta Agric. Scand. A Anim. Sci. 49:113-120.

Kung, L. Jr., S. Demarco, L. N. Siebenson, E. Joyner, G. F. W Haenlein, and R. M. Morris. 1997. An evaluation of two management systems for rearing calves fed milk replacer. J. Dairy Sci. $80: 2529-2533$

Lidfors, L., and L. Isberg. 2003. Intersucking in dairy cattle-Review and questionnaire. Appl. Anim. Behav. Sci. 80:207-231.

Lidfors, L. M. 1993. Cross-sucking in group-housed dairy calves before and after weaning off milk. Appl. Anim. Behav. Sci. 38:15-24.

Litherland, N. B., D. N. L. Da Silva, R. J. LaBerge, J. Schefers, and A. Kertz. 2014. Supplemental fat for dairy calves during mild cold stress. J. Dairy Sci. 97:2980-2989.
Loberg, J., and L. Lidfors. 2001. Effect of milk flow rate and presence of a floating nipple on abnormal sucking between dairy calves. Appl. Anim. Behav. Sci. 72:189-199.

Margerison, J. K., T. R. Preston, N. Berry, and C. J. C. Phillips. 2003. Cross-sucking and other oral behaviours in calves, and their relation to cow suckling and food provision. Appl. Anim. Behav. Sci 80:277-286.

Mitchell, H. H. 1928. Check formulas for surface area of sheep. Pages 155-158 in A Year's Progress in Solving Farm Problems in Illinois. Annu. Rep. Illinois Agric. Exp. Stn., Urbana.

NRC. 2001. Nutrient Requirements of Dairy Cattle. 7th rev. ed. National Academy Press, Washington, DC.

Rollin, B. E. 1996. The new ethic for animals and the dairy industry. Pages 4-18 in Proc. Natl. Mastitis Council, Nashville, TN. Natl. Mastitis Council Inc., Arlington, VA.

Rushen, J., A. M. de Passillé, M. A. G. von Keyserlingk, and D. M. Weary. 2010. The Welfare of Cattle. C. Phillips, ed. Springer Publishing. Dordrecht, the Netherlands.

Scibilia, L. S., L. D. Muller, R. S. Kensinger, T. F. Sweeney, and P. R. Shellenberger. 1987. Effect of environmental temperature and dietary fat on growth and physiological responses of newborn calves. J. Dairy Sci. 70:1426-1433.

Snedecor, W. S., and W. G. Cochran. 1967. Statistical Methods. Iowa Univ. Press, Ames, Iowa.

Soberon, F., E. Raffrenato, R. W. Everett, and M. E. Van Amburgh 2012. Preweaning milk replacer intake and effects on long-term productivity of dairy calves. J. Dairy Sci. 95:783-793.

USDA. 2012. Dairy heifer raiser, 2011: An overview of operations that specialize in raising dairy heifers. USDA-APHIS-VS-CEAHNAHMS. Fort Collins, CO.

Vasseur, E., J. Rushen, and A. M. de Passille. 2009. Does a calf's motivation to ingest colostrum depend on time since birth, calf vigor, or provision of heat? J. Dairy Sci. 92:3915-3921.

Weary, D. M., J. Jasper, and M. J. Hötzel. 2008. Understanding weaning distress. Appl. Anim. Behav. Sci. 110:24-41.

Xiccato, G., A. Trocino, P. I. Queaque, A. Sartori, and A. Carazzolo. 2001. Rearing veal calves with respect to animal welfare: Effects of group housing and solid feed supplementation on growth performance and meat quality. Livest. Prod. Sci. 75:269-280. 